\title{
Rituximab increases the risk of hepatitis B virus reactivation in non-Hodgkin lymphoma patients who are hepatitis $B$ surface antigen-positive or have resolved hepatitis B virus infection in a real-world setting
}

\author{
Yu-Fen Tsai ${ }^{1,2}$, Ching-I Yang ${ }^{1}$, Jeng-Shiun Du ${ }^{1}$, Ming-Hui Lin ${ }^{1}$, Shih-Hao Tang ${ }^{1}$, Hui-Ching Wang ${ }^{1}$, Shih-Feng \\ Cho ${ }^{1}$, Yi-Chang Liu ${ }^{1,3,4}$, Yu-Chieh Su ${ }^{1}$, Chia-Yen Dai ${ }^{3}$, Hui-Hua Hsiao ${ }^{\text {Corresp. } 1,3,4}$ \\ ${ }^{1}$ Division of Hematology and Oncology, Department of Internal Medicine, Kaohsiung Medical University Hospital, Kaohsiung Medical University, \\ Kaohsiung, Taiwan \\ 2 Graduate Institute of Medicine, College of Medicine,, Kaohsiung Medical University, Kaohsiung, Taiwan \\ 3 Faculty of Medicine, College of Medicine,, Kaohsiung Medical University, Kaohsiung, Taiwan \\ 4 Department of Laboratory Medicine, Kaohsiung Medical University Hospital, Kaohsiung, Taiwan \\ Corresponding Author: Hui-Hua Hsiao \\ Email address: huhuhs@cc.kmu.edu.tw
}

Background. Hepatitis B virus (HBV) reactivation with a hepatitis flare is a common complication in lymphoma patients treated with immunotherapy and/or chemotherapy. Anti-HBV prophylaxis is suggested for non-Hodgkin lymphoma (NHL) patients undergoing rituximab therapy, even those with resolved HBV infection. Since anti-HBV prophylaxis for patients with resolved HBV infection is not covered by national health insurance in Taiwan, a proportion of these patients receive no prophylaxis. In addition, late HBV reactivation has emerged as a new issue in recent reports, and no consensus has been reached for the optimal duration of anti-viral prophylaxis. Thus, the aim of our study was to investigate the incidence and outcomes of HBV reactivation in NHL patients in a real-world setting and to study the frequency of late HBV reactivation.

Materials. NHL patients who received rituximab and/or chemotherapy at our institute between January 2011 and December 2015 and who were hepatitis B surface antigen (HBsAg)- or hepatitis B core antibody (HBCAb)-positive were reviewed retrospectively.

Results. A total of 388 patients were screened between January 2011 and December 2015. In total, 196 patients were excluded because HBsAg was not assessed, HBcAb was negative or not assessed, or they were not treated with immunosuppressive therapy. Finally, the retrospective study included $62 \mathrm{HBsAg}$ positive NHL patients and $130 \mathrm{NHL}$ patients with resolved HBV infection(HBsAg-negative and HBcAbpositive). During a median 30.5-month follow-up period, seven patients experienced HBV reactivation, five of whom had a hepatitis flare. The incidence of HBV reactivation did not significantly differ between the HBsAg-positive patients and the resolved HBV infection population without anti-HBV prophylaxis( $4.8 \%$ vs. 3.1\%, $P=0.683$ ). All patients with HBV reactivation were exposed to rituximab. Notably, late HBV reactivation was not uncommon (two of seven patients with HBV reactivation events, $28.6 \%)$. HBV reactivation did not influence the patients' overall survival. An age $\geq 65$ years and an advanced disease stage were independent risk factors for poorer overall survival.

Conclusion. The incidence of HBV reactivation was similar between the HBsAg-positive patients with anti-viral prophylaxis and the resolved HBV infection population without anti-HBV prophylaxis. All HBV reactivation events occurred in NHL patients exposed to rituximab. Late reactivation was not uncommon.

Peer) reviewing PDF | (2019:03:35793:1:0:REVIEW 23 Jun 2019) 
The duration of regular liver function monitoring for more than one year after immunosuppressive therapy or after withdrawal of prophylactic antiviral therapy should be prolonged. Determining the exact optimal duration of anti-HBV prophylaxis is warranted in a future prospective study for NHL patients treated with rituximab containing therapy. 
1 Rituximab increases the risk of hepatitis $B$ virus reactivation in non-Hodgkin lymphoma

2 patients who are hepatitis $B$ surface antigen-positive or have resolved hepatitis $B$ virus

3 infection in a real-world setting

6 Yu-Fen Tsai ${ }^{1,2}$, Ching-I Yang ${ }^{1}$, Jeng-Shiun Du ${ }^{1}$, Ming-Hui Lin ${ }^{1}$, Shih-Hao Tang ${ }^{1}$, Hui-Ching

7 Wang ${ }^{1}$, Shih-Feng Cho ${ }^{1,3}$, Yi-Chang Liu ${ }^{1,3,4}$, Yu-Chieh Su${ }^{1}$, Chia-Yen Dai ${ }^{3}$, Hui-Hua Hsiao ${ }^{1,3,4^{*}}$

$9{ }^{1}$ Division of Hematology and Oncology, Department of Internal Medicine, Kaohsiung Medical

10 University Hospital, Kaohsiung Medical University, Kaohsiung, Taiwan

$11{ }^{2}$ Graduate Institute of Medicine, College of Medicine, Kaohsiung Medical University,

12 Kaohsiung, Taiwan

$13{ }^{3}$ Faculty of Medicine, College of Medicine, Kaohsiung Medical University, Kaohsiung, Taiwan.

$14{ }^{4}$ Department of Laboratory Medicine, Kaohsiung Medical University Hospital, Kaohsiung,

15 Taiwan.

17 Corresponding Author:

18 Hui-Hua Hsiao ${ }^{1,3,4}$,

19 No.100, Tzyou 1st Road, Kaohsiung 80708, Taiwan

20 E-mail: huhuhs@cc.kmu.edu.tw

21 
30 Abstract

31 Background. Hepatitis B virus (HBV) reactivation with a hepatitis flare is a common

32 complication in lymphoma patients treated with immunotherapy and/or chemotherapy. Anti-

33 HBV prophylaxis is suggested for non-Hodgkin lymphoma (NHL) patients undergoing rituximab

34 therapy, even those with resolved HBV infection. Since anti-HBV prophylaxis for patients with

35 resolved HBV infection is not covered by national health insurance in Taiwan, a proportion of

36 these patients receive no prophylaxis. In addition, late HBV reactivation has emerged as a new

37 issue in recent reports, and no consensus has been reached for the optimal duration of anti-viral

38 prophylaxis. Thus, the aim of our study was to investigate the incidence and outcomes of HBV

39 reactivation in NHL patients in a real-world setting and to study the frequency of late HBV

40 reactivation.

41

Materials. NHL patients who received rituximab and/or chemotherapy at our institute between January 2011 and December 2015 and who were hepatitis B surface antigen (HBsAg)- or hepatitis B core antibody ( $\mathrm{HBc} \mathrm{Ab})$-positive were reviewed retrospectively.

Results. A total of 388 patients were screened between January 2011 and December 2015. In total, 196 patients were excluded because HBsAg was not assessed, HBcAb was negative or not assessed, or they were not treated with immunosuppressive therapy. Finally, the retrospective study included 62HBsAg-positive NHL patients and 130 NHL patients with resolved HBV infection(HBsAg-negative and HBcAb-positive). During a median 30.5-month follow-up period, seven patients experienced HBV reactivation, five of whom had a hepatitis flare. The incidence of HBV reactivation did not significantly differ between the HBsAg-positive patients and the resolved HBV infection population without anti-HBV prophylaxis( $4.8 \%$ vs. $3.1 \%, P=0.683)$. All patients with HBV reactivation were exposed to rituximab. Notably, late HBV reactivation was not uncommon (two of seven patients with HBV reactivation events, 28.6\%). HBV reactivation did not influence the patients' overall survival. An age $\geq 65$ years and an advanced disease stage were independent risk factors for poorer overall survival. 
59 Conclusion

60 The incidence of HBV reactivation was similar between the HBsAg-positive patients with anti-

61 viral prophylaxis and the resolved HBV infection population without anti-HBV prophylaxis. All

62 HBV reactivation events occurred in NHL patients exposed to rituximab. Late reactivation was

63

64

65

66

67

68

69

70 not uncommon. The duration of regular liver function monitoring for more than one year after immunosuppressive therapy or after withdrawal of prophylactic antiviral therapy should be prolonged. Determining the exact optimal duration of anti-HBV prophylaxis is warranted in a future prospective study for NHL patients treated with rituximab containing therapy.

\section{Introduction}

Hepatitis B virus (HBV) infection is a primary cause of chronic liver disease, liver cirrhosis, and hepatocellular carcinoma. Approximately $15-20 \%$ of adults in Taiwan are chronically infected with HBV(Sung,1984;Gust, 1996), and chronic liver disease and cirrhosis was the tenth leading cause of death in 2017. Therefore, Taiwan is a hyperendemic area for HBV infection, and HBV infection is an important health issue in Taiwan.

According to the guideline from the American Association for the Study of Liver Disease (AASLD), HBV reactivation in hepatitis B surface antigen (HBsAg)-positive patients is defined as a $\geq 2 \log$ increase in HBV DNA compared to baseline or an HBV DNA level $\geq 1000 \mathrm{IU} / \mathrm{mL}$ in patients with previously undetectable levels. HBV reactivation in patients with resolved HBV infections is defined as the reappearance of HBsAg or detectable HBV DNA. A hepatitis flare is defined as an increase in alanine aminotranferase (ALT) to greater than or equal to three times the baseline level and>100 IU/L (Terrault et al., 2018).

Reports of HBV reactivation after rituximab therapy started emerging a few years after FDA approval.HBV reactivation and hepatitis flares are well known complications in cancer patients receiving chemotherapy. The combination regimen of rituximab and cytotoxic chemotherapy has also been found to increase the risk of hepatitis B reactivation, even in patients in whom HBV infection is resolved (i.e., HBsAg-negative but hepatitis B core antibody [HBcAb]-positive)(Dong et al., 2013; Evens et al., 2011; Yeo et al., 2009).Due to the high prevalence rate of chronic HBV infection in Taiwan, HBV reactivation-related complications are a great concern in lymphoma patients receiving rituximab and chemotherapy.

The recently published guidelines from the European Association for the Study of the Liver 
90 (EASL) and the AASLD both recommend that patients undergoing rituximab therapy receive

91 anti-HBV prophylaxis(Lampertico et al., 2017; Terrault et al., 2018). However, the

92 recommended duration of anti-HBV prophylaxis is not consistent. Whereas the AASLD suggests

93 that anti-HBV prophylaxis should continue for at least six months (or for at least 12 months for

94 patients receiving rituximab) after the completion of immunosuppressive therapy, the EASL

95 suggests that prophylaxis should continue for at least 12 months (or for at least 18 months for

96 rituximab-based therapy). Moreover, late HBV reactivation (i.e., reactivation more than 12

97 months after completing immunosuppressive therapy(Nakaya et al., 2016) or after withdrawal of

98 prophylactic antiviral therapy(Liu et al., 2016)) has been reported recently. However, the optimal

99 duration of anti-HBV prophylaxis has not been determined. Furthermore, because anti-HBV

100 prophylaxis for patients with resolved HBV infection is not covered by national health insurance

101 in Taiwan, prophylactic anti-HBV therapy is not prescribed routinely to these patients.

102 Therefore, we performed a retrospective study to understand the reality of HBV reactivation in

103 patients with resolved HBV infection and to investigate the incidence and outcomes of HBV

104 reactivation and late HBV reactivation in HBsAg-positive NHL patients and in NHL patients

105 with resolved HBV infections who were being treated with rituximab and/or chemotherapy.

106

107 Materials \& Methods

108 Patients and study design

109 We performed a retrospective observational study of patients newly diagnosed with NHL at

110 Kaohsiung Medical University Hospital between January 2011 and December 2015. The

111 inclusion criteria were as follows: 1) age 20 years or older, 2) received at least one cycle of

112 rituximab and/or chemotherapy, and 3) were initially either HBsAg- or HBcAb-positive. The

113 collected data included demographics, histological subtypes, treatment choice, hepatitis virus

114 serology, HBV DNA level, and patient outcome. The baseline hepatitis virus serology and the

115 ALT and HBV DNA level were tested during the time interval from the diagnosis of lymphoma

116 to the first treatment. HBsAg-positive patients took their anti-viral prophylaxis until six months

117 after cessation of chemotherapy, which was covered by national health insurance. HBsAg-

118 positive patients received regular follow-up evaluations of their hepatitis virus serology and

119 HBV DNA levels every three months, whereas patients with resolved HBV infection only

120 received hepatitis virus serological testing when the ALT level became abnormal. Overall

Peer] reviewing PDF | (2019:03:35793:1:0:REVIEW 23 Jun 2019) 
121 survival was defined as the length of time from the date of diagnosis to the last date of follow-up

122 or death. All patients were followed up until February 2017.

123 Informed consent was not needed because the study was a retrospective chart review. The study

124 was approved by the Institutional Review Board of Kaohsiung Medical University Hospital,

125 Kaohsiung, Taiwan, in 2016 (KMUHIRB-E(I)-20160009).

126

127 Statistical analysis

128 Patient characteristics and factors contributing to HBV reactivation were analyzed using

129 descriptive statistics and are presented as frequencies, percentages, and medians. Student's t-test

130 or nonparametric statistics were utilized to test for statistically significant differences in

131 continuous variables, whereas the chi-square or Fisher's exact test was used for categorical

132 variables. Overall survival was estimated using the Kaplan-Meier method. Variables that were

133 statistically significant $(P<0.05)$ in the univariate analysis of survival were subsequently

134 subjected to multivariate analysis using a Cox regression model. A two-tailed $P$-value $<0.05$ was

135 considered statistically significant.

136

\section{Results}

138 Patient characteristics

139 A total of 388 patients were diagnosed with NHL between January 2011 and December

140 2015. Seventy patients were positive for $\mathrm{HBsAg}$, and 310 were negative. Among the HBsAg-

141 negative patients, 158 were positive for $\mathrm{HBcAb}, 130$ of whom received at least one cycle of

142 rituximab or chemotherapy and thus were included in the study. Among the HBsAg-positive

143 patients, 62 received at least one cycle of rituximab or chemotherapy and were also included. A

144 flowchart of the patient selection process is shown in Figure 1.

145 Among all included patients, 54.7\% were male, and the median age at the time of diagnosis

146 was 62 years (range, 27-90 years). The median length of follow-up was 30.5 months (range 0.8-

14773.9 months). The baseline patient characteristics are summarized in Table 1. The HBsAg-

148 positive group exhibited a lower proportion of patients who were positive for HBsAb than the

149 HBsAg-negative/HBcAb-positive group (i.e., the resolved HBV infection) (14.5\% vs. 72.3\%,

$150 P<0.001)$ and was the only group to receive prophylactic anti-viral therapy $(98.4 \% \mathrm{vs.} 0 \%$, 
$151 P<0.001)$. No differences were found in the age, sex, lymphoma subtype, stage, rituximab use,

152 and HBV reactivation rate between these two groups.

153

154 Incidence of $\mathrm{HBV}$ reactivation and $\mathrm{HBV}$-related hepatitis flares

155 Overall, seven patients developed HBV reactivation with an incidence rate of 3.6\%, and

156 five patients experienced an HBV-related hepatitis flare. Three of the seven patients with HBV

157 reactivation were $\mathrm{HBs} A g$-positive, and four had a resolved $\mathrm{HBV}$ infection at the initial

158 diagnosis. The incidence rates of HBV reactivation in the HBsAg-positive and resolved HBV

159 infection groups were $4.8 \%$ and $3.1 \%$, respectively, which were not significantly different.

160

161

Factors associated with $\mathrm{HBV}$ reactivation

162 The factors attributed to HBV reactivation are compared in Table 2. Most patients

163 experiencing HBV reactivation were older ( $\geq 60$ years), had advanced-stage disease, and were

164 predominantly male. All patients who experienced HBV reactivation received rituximab-

165 containing treatment.

166

167

$\mathrm{HBV}$ reactivation and $\mathrm{HBV}$-related hepatitis flares in the $\mathrm{HBs} A g$-positive patients

168

Three of the $62 \mathrm{HBsAg-positive} \mathrm{patients} \mathrm{developed} \mathrm{HBV} \mathrm{reactivation.} \mathrm{The} \mathrm{details} \mathrm{for} \mathrm{these}$ three patients are shown in Table 3. Two of these patients were male. All patients were in the advanced stage four, received multiple cycles of rituximab-containing treatment, and were receiving a different antiviral agent than that prescribed for their previous prophylaxis. Two patients developed a hepatitis flare. Patient number one received entecavir for 7.9 months, and their hepatitis was resolved without a detectable HBV DNA level. Patient number three received both tenofovir and entecavir but still died of fatal fulminant hepatitis attributed to HBV reactivation (although this patient also had comorbid hepatocellular carcinoma).

\section{Comparison of $\mathrm{HBV}$ reactivation rates between subgroups divided based on antiviral} prophylaxis

Sixty-one of the 62 (98.4\%) HBsAg-positive patients received anti-HBV prophylaxis. The anti-HBV prophylactic drugs administered to the HBsAg-positive patients included entecavir (35 of $61,57.4 \%$ ), tenofovir (13 of 61, 21.3\%), lamivudine (nineof $61,14.7 \%$ ), and telbivudine (four 
182 of $61,6.6 \%$ ). A higher HBV reactivation rate (one of nine, $11.1 \%$ ) was found in the patients who

183 used lamivudine as antiviral prophylaxis than in those who used entecavir, tenovir, or telbivudine 184 (two of 52, 3.8\%).

185

$\mathrm{HBV}$ reactivation and $\mathrm{HBV}$-related hepatitis flares in the patients with resolved $\mathrm{HBV}$ infections

Four of 130 patients with resolved HBV developed HBV reactivation; these patients are presented in Table 4.Three patients were diagnosed with a hepatitis flare, all of whom recovered after antiviral treatment (only one used lamivudine alone, whereas the other three patients used tenofovir or entecavir). Among these four HBV reactivated patients, three were male and had stage four disease. All patients were exposed to multiple cycles of rituximab-containing chemotherapy. One patient died of lymphoma progression not associated with a hepatitis flare.

\section{Late $\mathrm{HBV}$ reactivation}

Two patients experienced late HBV reactivation. The probability of late HBV reactivation was not uncommon in the patients who experienced a reactivation event $(28.6 \%)$. One patient had HBV that was initially resolved but reactivated 36.3 months after completing R-CHOP (rituximab with cyclophosphamide, doxorubicin, vincristine, and prednisolone) treatment; the other was initially HBsAg-positive and experienced HBV reactivation 11.2 months after withdrawal of prophylactic antiviral therapy.

202

Overall survival of NHL patients

The five-year overall survival rate was $71.0 \%$ based on the Kaplan-Meier analysis. The survival plot is shown in Figure 2. We ran a Cox regression model to analyze factors influencing the patients' mortality (Table 5). The variables with a significant effect on mortality in the univariate analysis were included in the multivariate analysis. An older age (hazard ratio [HR] $1.03,95 \%$ confidence interval [CI] 1.01-1.06, $P=0.005)$ and advanced disease stage (HR 4.21, 95\% CI 1.78-9.95, $P=0.001)$ were associated with inferior survival, whereas the HBsAg status, HBV reactivation, and hepatitis flare did not influence overall survival. 


\section{Discussion}

212 Our study provided real-world data for the incidence and outcomes of HBV reactivation and

213 hepatitis flares in NHL patients. We found that the overall incidence of HBV reactivation was

$2143.6 \%$; the incidence rates of HBV reactivation in the HBsAg-positive group (receiving

215 prophylaxis) and the resolved HBV infection group (which did not receive prophylaxis)

216 were $4.8 \%$ and $3.1 \%$, respectively, which were not significantly different.

217 A retrospective Asia Lymphoma Study Group (ALSG) study of HBV reactivation in

218 lymphoma patients revealed that this event occurred in 27.8\% of HBsAg-positive patients and

219 was significantly less frequent in patients receiving antiviral prophylaxis than in those not

220 receiving it (22.9\% vs. 59.1\%; $P<0.001)$ (Kim et al., 2013).By comparison, we observed a

221 significantly lower HBV reactivation rate (only 4.8\%) in our HBsAg-positive patients, 98.4\% of

222 whom received prophylactic anti-viral therapy. Lamivudine has proven to be a useful drug to

223 prevent HBV reactivation in patients undergoing chemotherapy for NHL(Persico et al., 2002).

224 However, several studies demonstrated that patients receiving second-line entecavir as a

225 prophylactic agent exhibited a significantly lower HBV reactivation rate than those receiving

226 lamivudine(Chen et al., 2013; Chen et al., 2015; Huang et al., 2014; Li et al., 2011).Furthermore,

227 the AASLD 2018 hepatitis B guidelines recommended entecavir and tenofovir as the preferred

228 first-line anti-HBV agents because of their higher potency and barrier to resistance (Terrault et

229 al., 2018). Notably, most patients in the ALSG study used lamivudine, whereas more than 75\%

230 of the patients in our study were treated with entecavir and tenofovir for HBV prophylaxis. In

231 addition, a higher HBV reactivation rate (11.1\%) was noted in patients who used lamivudine as

232 antiviral prophylaxis than in those who used entecavir, tenovir, or telbivudine (3.8\%). This result

233 may explain the lower HBV reactivation rate (4.8\%) in our HBsAg-positive patients.

234 Among the population with resolved HBV infections in the ALSG study, 9.6\% developed

235 HBV reactivation (Kim et al., 2013), whereas the HBV reactivation rate in our study was $3.1 \%$.

236 Several studies have found that HBsAb negativity or a low titer is a risk factor for HBV

237 reactivation (Cho et al., 2016; Matsubara et al., 2017; Seto et al., 2014; Yeo et al., 2009).The

238 higher percentage (72.3\%) of HBsAb-positive patients in our resolved HBV infection group than

239 in our HBsAg-positive group might partially explain why these patients did not experience a

240 higher HBV reactivation rate even in the absence of anti-HBV prophylaxis. Another key factor

241 was that we did not routinely monitor the HBV DNA and ALT levels in the patients with 
242 resolved HBV infections and only tested their HBV status upon detecting abnormal liver

243 function. This strategy may have led to underestimation of the incidence of HBV reactivation in

244 our resolved HBV infection group.

245 Regarding the features of the patients who experienced HBV reactivation, receiving a

246 rituximab-containing regimen, an older age ( $\geq 60$ years), male sex, and an advanced disease stage

247 were associated with HBV reactivation. All patients who experienced HBV reactivation received

248 rituximab for at least five cycles; this finding was consistent with a recent meta-analysis that

249 revealed a significantly higher rate of HBV reactivation (8.2\%) in patients receiving rituximab-

250 containing chemotherapy than in those not receiving rituximab (0.6\%)(Evens et al., 2011). In

251 addition, a study focused on elderly (age $>65$ years) NHL patients with resolved HBV infections

252 also reported that HBV reactivation was more likely to occur after an average of five R-

253 CHOP cycles(Castelli et al., 2016). These findings all implied that multiple cycles of rituximab-

254 containing chemotherapy was the key factor for HBV reactivation.

255 One patient died due to HBV reactivation-induced fatal fulminant hepatitis. However, the

256 patient also had an underlying hepatocellular carcinoma malignancy. The remaining four

257 hepatitis flare patients resolved after antiviral treatment, and three achieved an undetectable

258 HBV DNA level. Overall, HBV reactivation and hepatitis flares did not compromise patient

259 survival in our study. This result was consistent with a previous study conducted in north Taiwan

260 in which HBV reactivation was associated with a greater number of cycles (greater than or equal

261 to six) and a prolonged duration of rituximab therapy; overall survival in that study did not differ

262 between patients with versus those without HBV reactivation (Hsiao et al., 2015). In our study,

263 an age $\geq 60$ years and Ann Arbor stages III-IV were two independent negative prognostic factors.

264 The EASL and AASLD guidelines both recommend that patients who undergo rituximab

265 therapy should receive anti-HBV prophylaxis(Lampertico et al., 2017; Terrault et al., 2018);

266 however, the optimal duration of such prophylaxis remains uncertain and has varied from six to

26718 months after completion of immunosuppressive therapy. A retrospective study conducted by

268 Liu et al. (2016) found that the incidence rate of HBV reactivation after withdrawal of

269 prophylactic antiviral therapy was $21.7 \%$ and that the median time from the withdrawal of the

270 prophylactic antiviral therapy to HBV reactivation was 2.9 months (range, 1.1-8.5)(Liu et al.,

271 2016).However, several studies also reported that patients developed late HBV reactivation (i.e.,

272 more than one year post-therapy)(Lee et al., 2010; Muraishi et al., 2017; Nakaya et al., 2016; 
273 Yamada et al., 2017). The literature review of Yamada et al.(2017) revealed that an advanced

274 disease stage, lymphoid malignancies, and treatment with multiple courses of rituximab-

275 containing therapies were associated with late HBV reactivation (Yamada et al., 2017).In our

276 study, late HBV reactivation accounted for $28.6 \%$ of the total HBV reactivation events and thus

277 was not as rare as we expected. The longest time to HBV reactivation after completion of

278 rituximab-containing therapy was 36.3 months. Hence, these data indicate that close monitoring

279 of the HBV DNA and ALT levels remains important even at one year after completing

280 rituximab-containing therapy or withdrawal of prophylactic anti-viral therapy. Identifying

281 patients at a high risk of late HBV reactivation and determining the optimal duration of

282 prophylaxis for high-risk populations are pivotal aims that require further study.

283 Although we obtained notable results, our study had some limitations. First, our study was a

284 retrospective observational study with a small number of patients in each group. Second, the

285 differing chemotherapy regimens and doses may have constituted confounding factors in terms

286 of HBV reactivation. Third, the resolved HBV infection group did not receive routine follow-up

287 (including liver function and HBV statuses). However, our study provides clinicians the real-

288 world data for HBV reactivation and reminds them of the possibility of late HBV reactivation.

289

\section{Conclusions}

291 The incidence of HBV reactivation is similar between HBsAg-positive patients with anti-

292 viral prophylaxis and patients with resolved HBV infections without anti-HBV prophylaxis.

293 Rituximab exposure is a key risk factor for HBV reactivation. Late HBV reactivation is not as

294 rare as we expected, and regular monitoring of the HBV DNA and ALT levels is important even

295 one year after withdrawal of immunosuppressive therapy or prophylactic anti-viral therapy.

296 Prospective studies are required to determine the optimal duration of prophylaxis for patients at

297 high risk of late HBV reactivation.

298

299

300

301 References

302 Castelli R, Ferraris L, Pantaleo G, Lambertenghi Deliliers G, and Cicardi M. 2016. High rate of hepatitis B viral breakthrough in elderly non-Hodgkin lymphomas patients treated with 
304

305

306

307

308

309

310

311

312

313

314

315

316

317

318

319

320

321

322

323

324

325

326

327

328

329

330

331

332

333

Rituximab based chemotherapy. Dig Liver Dis 48:1394-1397. DOI:

10.1016/j.dld.2016.08.113

Chen FW, Coyle L, Jones BE, and Pattullo V. 2013. Entecavir versus lamivudine for hepatitis B prophylaxis in patients with haematological disease. Liver Int 33:1203-1210. DOI: 10.1111/liv.12154

Chen WC, Cheng JS, Chiang PH, Tsay FW, Chan HH, Chang HW, Yu HC, Tsai WL, Lai KH, and Hsu PI. 2015. A comparison of entecavir and lamivudine for the prophylaxis of hepatitis B virus reactivation in solid tumor patients undergoing systemic cytotoxic chemotherapy. PLoS One 10:e0131545. DOI: 10.1371/journal.pone.0131545

Cho Y, Yu SJ, Cho EJ, Lee JH, Kim TM, Heo DS, Kim YJ, and Yoon JH. 2016. High titers of anti-HBs prevent rituximab-related viral reactivation in resolved hepatitis B patient with non-Hodgkin's lymphoma. J Med Virol 88:1010-1017. DOI: 10.1002/jmv.24423

Dong HJ, Ni LN, Sheng GF, Song HL, Xu JZ, and Ling Y. 2013. Risk of hepatitis B virus (HBV) reactivation in non-Hodgkin lymphoma patients receiving rituximabchemotherapy: a meta-analysis. J Clin Virol 57:209-214. DOI: 10.1016/j.jcv.2013.03.010

Evens AM, Jovanovic BD, Su YC, Raisch DW, Ganger D, Belknap SM, Dai MS, Chiu BC, Fintel B, Cheng Y, Chuang SS, Lee MY, Chen TY, Lin SF, and Kuo CY. 2011. Rituximab-associated hepatitis B virus (HBV) reactivation in lymphoproliferative diseases: meta-analysis and examination of FDA safety reports. Ann Oncol 22:11701180. DOI: $10.1093 /$ annonc/mdq583

Gust ID. 1996. Immunisation against hepatitis B in Taiwan. Gut38:S67-S68.DOI: 10.1136/gut.38.Suppl_2.S67

Hsiao LT, Chiou TJ, Gau JP, Yang CF, Yu YB, Liu CY, Liu JH, Chen PM, Tzeng CH, Chan YJ, Yang MH, and Huang YH. 2015. Risk of reverse seroconversion of hepatitis B virus surface antigen in rituximab-treated non-Hodgkin lymphoma patients: A large cohort retrospective study. Medicine (Baltimore) 94:e1321. DOI:

10.1097/md.0000000000001321

Huang H, Li X, Zhu J, Ye S, Zhang H, Wang W, Wu X, Peng J, Xu B, Lin Y, Cao Y, Li H, Lin S, Liu Q, and Lin T. 2014. Entecavir vs lamivudine for prevention of hepatitis B virus reactivation among patients with untreated diffuse large B-cell lymphoma receiving R- 
334

335

336

337

338

339

340

341

342

343

344

345

346

347

348

349

350

351

352

353

354

355

356

357

358

359

360

361

362

363

364

CHOP chemotherapy: a randomized clinical trial. JAMA 312:2521-2530. DOI: 10.1001/jama.2014.15704

Kim SJ, Hsu C, Song YQ, Tay K, Hong XN, Cao J, Kim JS, Eom HS, Lee JH, Zhu J, Chang KM, Reksodiputro AH, Tan D, Goh YT, Lee J, Intragumtornchai T, Chng WJ, Cheng AL, Lim ST, Suh C, Kwong YL, and Kim WS. 2013. Hepatitis B virus reactivation in Bcell lymphoma patients treated with rituximab: analysis from the Asia Lymphoma Study Group. Eur J Cancer 49:3486-3496.DOI: 10.1016/j.ejca.2013.07.006

Lampertico P, Agarwal K, Berg T, Buti M, Janssen HLA, Papatheodoridis G, Zoulim F, and Tacke F. 2017. EASL 2017 Clinical Practice Guidelines on the management of hepatitis B virus infection. J Hepatol 67:370-398. DOI:10.1016/j.jhep.2017.03.021

Lee IC, Huang YH, Chu CJ, Lee PC, Lin HC, and Lee SD. 2010. Hepatitis B virus reactivation after 23 months of rituximab-based chemotherapy in an HBsAg-negative, anti-HBspositive patient with follicular lymphoma. J Chin Med Assoc 73:156-160. DOI: 10.1016/s1726-4901(10)70031-9

Li HR, Huang JJ, Guo HQ, Zhang X, Xie Y, Zhu HL, Zhai LZ, Pu XX, Huang Y, Guo CC, and Lin TY. 2011. Comparison of entecavir and lamivudine in preventing hepatitis B reactivation in lymphoma patients during chemotherapy. $J$ Viral Hepat 18:877-883. DOI: 10.1111/j.1365-2893.2010.01386.x

Liu WP, Wang XP, Zheng W, Ping LY, Zhang C, Wang GQ, Song YQ, and Zhu J. 2016. Hepatitis B virus reactivation after withdrawal of prophylactic antiviral therapy in patients with diffuse large B cell lymphoma. Leuk Lymphoma 57:1355-1362. DOI: $10.3109 / 10428194.2015 .1116121$

Matsubara T, Nishida T, Shimoda A, Shimakoshi H, Amano T, Sugimoto A, Takahashi K, Mukai K, Yamamoto M, Hayashi S, Nakajima S, Fukui K, and Inada M. 2017. The combination of anti-HBc and anti-HBs levels is a useful predictor of the development of chemotherapy-induced reactivation in lymphoma patients with resolved HBV infection. Oncol Lett 14:6543-6552.DOI: 10.3892/o1.2017.7012

Muraishi J, Shibata M, Honma Y, Hiura M, Abe S, and Harada M. 2017. Reactivation of occult hepatitis B virus infection 27 months after the end of chemotherapy including rituximab for malignant lymphoma. Intern Med 56:1967-1971.DOI:

10.2169/internalmedicine.56.8233

Peer] reviewing PDF | (2019:03:35793:1:0:REVIEW 23 Jun 2019) 
365 Nakaya A, Fujita S, Satake A, Nakanishi T, Azuma Y, Tsubokura Y, Hotta M, Yoshimura H,

366 Ishii K, Ito T, and Nomura S. 2016. Delayed HBV reactivation in rituximab-containing

367

368

369

370

371

372

373

374

375

376

377

378

379

380

381

382

383

384

385

386

387

388

389

390

391 chemotherapy: How long should we continue anti-virus prophylaxis or monitoring HBVDNA? Leuk Res 50:46-49. DOI: 10.1016/j.leukres.2016.09.014

Persico M, De Marino F, Russo GD, Morante A, Rotoli B, Torella R, and De Renzo A. 2002. Efficacy of lamivudine to prevent hepatitis reactivation in hepatitis B virus-infected patients treated for non-Hodgkin lymphoma. Blood 99:724-725. DOI: 10.1182/blood.v99.2.724

Seto WK, Chan TS, Hwang YY, Wong DK, Fung J, Liu KS, Gill H, Lam YF, Lie AK, Lai CL, Kwong YL, and Yuen MF. 2014. Hepatitis B reactivation in patients with previous hepatitis B virus exposure undergoing rituximab-containing chemotherapy for lymphoma: a prospective study. J Clin Oncol 32:3736-3743. DOI:

$10.1200 /$ jco.2014.56.7081

Sung, JL. 1984. Hepatitis B virus infection and its sequelae in Taiwan.Gastroenterol Jpn 19:363366. DOI: $10.1007 / \mathrm{BF} 02779126$

Terrault NA, Lok ASF, McMahon BJ, Chang KM, Hwang JP, Jonas MM, Brown RS, Jr., Bzowej NH, and Wong JB. 2018. Update on prevention, diagnosis, and treatment of chronic hepatitis B: AASLD 2018 hepatitis B guidance. Hepatology 67:1560-1599. DOI: 10.1002/hep. 29800

Yamada T, Nannya Y, Suetsugu A, Shimizu S, Sugihara J, Shimizu M, Seishima M, and Tsurumi H. 2017. Late reactivation of hepatitis B virus after chemotherapies for hematological malignancies: A case report and review of the literature. Intern Med 56:115-118. DOI: 10.2169/internalmedicine.56.7468

Yeo W, Chan TC, Leung NW, Lam WY, Mo FK, Chu MT, Chan HL, Hui EP, Lei KI, Mok TS, and Chan PK. 2009. Hepatitis B virus reactivation in lymphoma patients with prior resolved hepatitis B undergoing anticancer therapy with or without rituximab. J Clin Oncol 27:605-611. DOI: 10.1200/jco.2008.18.0182 


\section{Figure 1}

\section{Flow chart of patient selection}

Abbreviations: HBsAg, hepatitis B surface antigen; $\mathrm{HBcAb}$, hepatitis B core antibody; $H$.

pylori, Helicobacter pylori

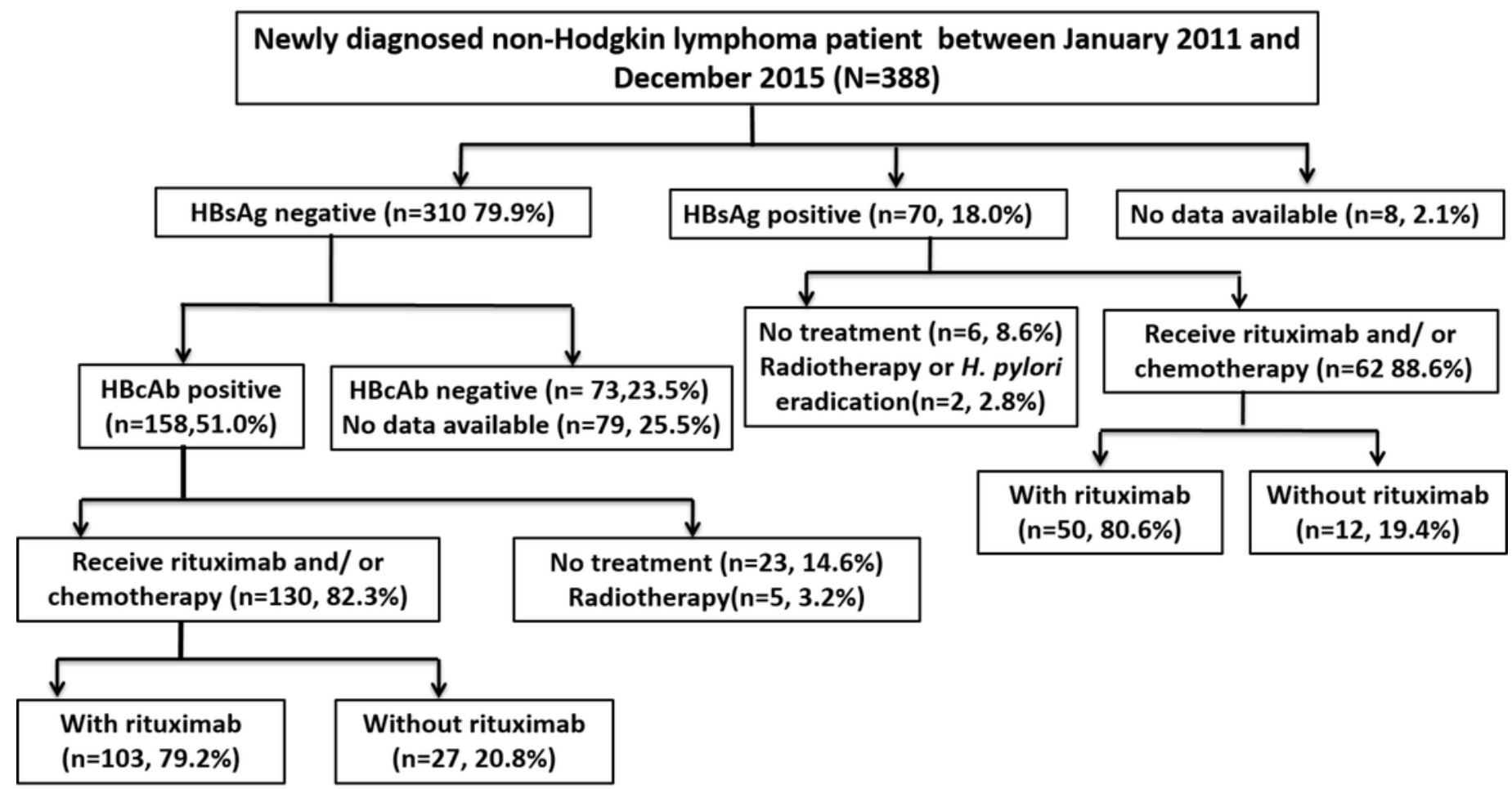


Figure 2

Kaplan-Meier survival curve of overall survival for all patients

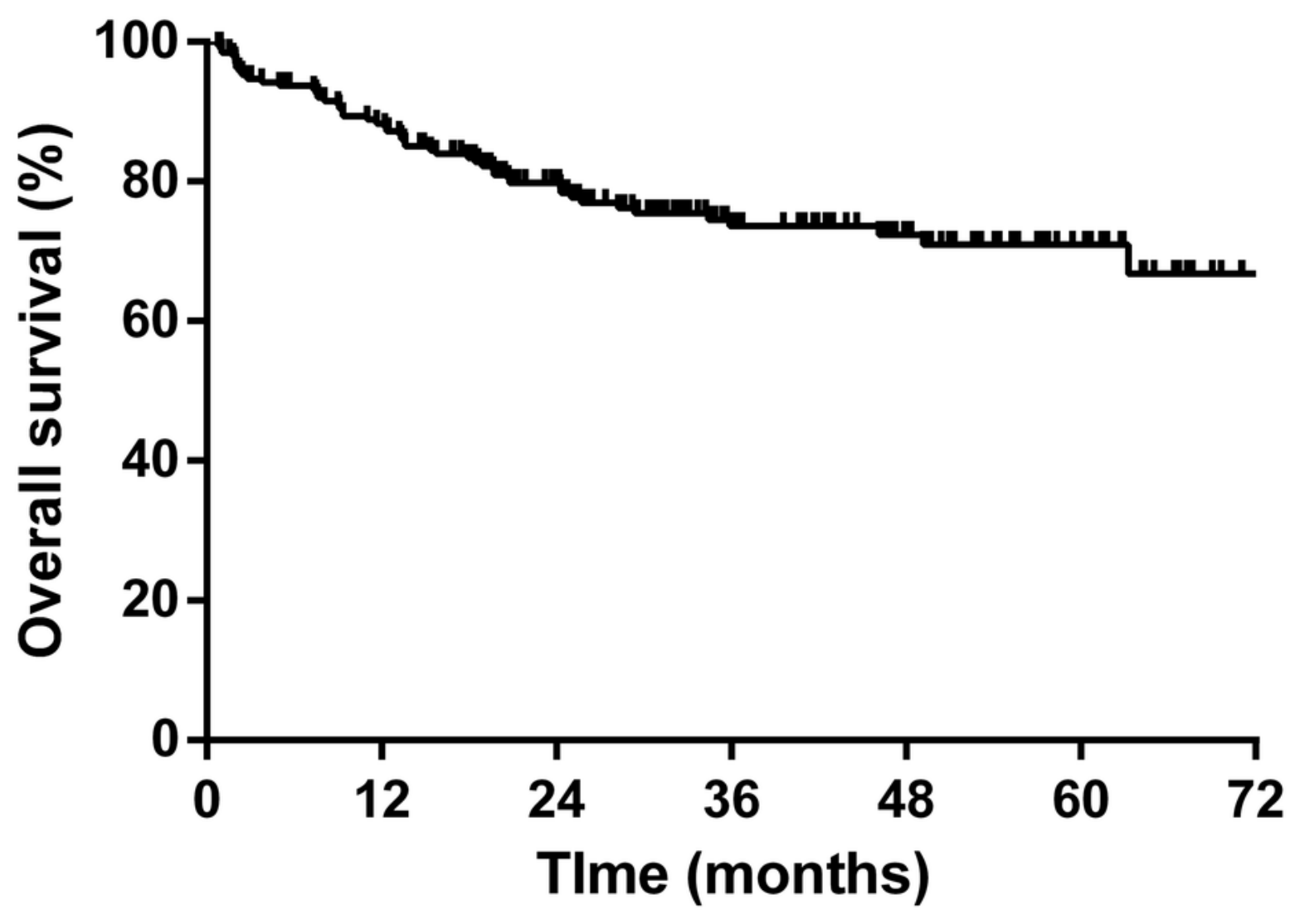




\section{Table 1 (on next page)}

Baseline characteristics in non-Hodgkin lymphoma patients who received rituximab and/or chemotherapy 
Table 1. Baseline characteristics in non-Hodgkin lvmphoma patients who received rituximab and/or chemotherapy

\begin{tabular}{|c|c|c|c|c|}
\hline & All patients & HBsAg-positive group & HBsAg-negative/HBcAb-positive & $P$-value \\
\hline Sex & & & & 0.977 \\
\hline Male & $105(54.7)$ & $34(54.8)$ & $71(54.6)$ & \\
\hline Female & $87(45.3)$ & $28(45.2)$ & $59(45.4)$ & \\
\hline Age (years)(median, range) & $62(27-90)$ & $56(27-83)$ & $63(28-90)$ & 0.885 \\
\hline $\mathrm{HBsAb}$ & & & & 0.000 \\
\hline Positive & $103(53.6)$ & $9(14.5)$ & $94(72.3)$ & \\
\hline Negative & $75(39.1)$ & $49(79.0)$ & $26(20.0)$ & \\
\hline Data unavailable & $14(7.3)$ & $4(6.5)$ & $10(7.7)$ & \\
\hline Lymphoma subtype & & & & 0.494 \\
\hline DLBCL & $118(61.5)$ & $36(58.1)$ & $82(63.1)$ & \\
\hline FL & 19(9.9) & $8(12.9)$ & $11(8.5)$ & \\
\hline Marginal zone lymphoma & $21(10.9)$ & $7(11.3)$ & $14(10.8)$ & \\
\hline $\mathrm{T}$ cell lymphoma & $10(5.2)$ & $1(1.6)$ & $9(6.9)$ & \\
\hline MALToma & $9(4.7)$ & $4(6.5)$ & $5(3.8)$ & \\
\hline Mantle cell lymphoma & $7(3.6)$ & $2(3.2)$ & $5(3.8)$ & \\
\hline Burkitt lymphoma & $1(0.5)$ & 0 & $1(0.8)$ & \\
\hline Other B cell lymphoma ${ }^{a}$ & $7(3.6)$ & $4(6.5)$ & $3(2.3)$ & \\
\hline Stage & & & & 0.194 \\
\hline I & $31(16.1)$ & $13(21.0)$ & $18(13.8)$ & \\
\hline II & $32(16.7)$ & $6(9.7)$ & $26(20.0)$ & \\
\hline III & $42(21.9)$ & $12(19.4)$ & $30(23.1)$ & \\
\hline IV & $87(45.3)$ & $31(50.0)$ & $56(43.1)$ & \\
\hline With rituximab therapy & $153(79.7)$ & $50(80.6)$ & $103(79.2)$ & 0.820 \\
\hline Prophylaxis with anti-HBV agents & $61(31.8)$ & $61(98.4)$ & $0(0)$ & 0.000 \\
\hline HBV reactivation & $7(3.6)$ & $3(4.8)$ & $4(3.1)$ & 0.683 \\
\hline
\end{tabular}

1 a Other B cell lymphomas: 1 B cell lymphoma, 1 large B cell lymphoma, 1 B-cell lymphoma, unclassifiable with features intermediate between diffuse large B-

2 cell lymphoma and classical Burkitt's lymphoma, 1 lymphoplasmacytic lymphoma, 1 plasmablastic lymphoma, and 2 small lymphocytic lymphoma.

3 Abbreviations: DLBCL, diffuse large B cell lymphoma; FL, follicular lymphoma; MALT, mucosa associated lymphoid tissue; HBV, hepatitis B virus; HBsAg,

4 hepatitis B surface antigen; HBcAb, hepatitis B core antibody; HBsAb, hepatitis B surface antibody. 


\section{Table 2 (on next page)}

Factors influencing HBV reactivation in NHL patients under rituximab and/or chemotherapy treatment 
1 Table 2. Factors influencing HBV reactivation in NHL patients under rituximab and/or chemotherapy treatment

\begin{tabular}{|c|c|c|c|c|c|c|c|c|c|c|c|c|}
\hline \multirow{3}{*}{ Factors } & \multicolumn{4}{|c|}{ All patients } & \multicolumn{4}{|c|}{ HBsAg positive } & \multicolumn{4}{|c|}{ HBsAg negative/HBcAb positive } \\
\hline & \multicolumn{2}{|c|}{ HBV reactivation } & \multicolumn{2}{|c|}{ No HBV reactivation } & \multicolumn{2}{|c|}{ HBV reactivation } & \multicolumn{2}{|c|}{ No HBV reactivation } & \multicolumn{2}{|c|}{ HBV reactivation } & \multicolumn{2}{|c|}{ No HBV reactivation } \\
\hline & $\mathrm{N}=7$ & $\%$ & $\mathrm{~N}=185$ & $\%$ & $\mathrm{~N}=3$ & $\%$ & $\mathrm{~N}=59$ & $\%$ & $\mathrm{~N}=4$ & $\%$ & $\mathrm{~N}=126$ & $\%$ \\
\hline$<60$ & 2 & 28.6 & 82 & 44.3 & 1 & 33.3 & 35 & 59.3 & 1 & 25.0 & 47 & 37.3 \\
\hline$\geq 60$ & 5 & 71.4 & 103 & 55.7 & 2 & 66.7 & 24 & 40.7 & 3 & 75.0 & 79 & 62.7 \\
\hline \multicolumn{13}{|l|}{ Sex } \\
\hline Female & 2 & 28.6 & 85 & 45.9 & 1 & 33.3 & 27 & 45.8 & 1 & 25.0 & 58 & 46.0 \\
\hline \multicolumn{13}{|c|}{ Ann Arbor stage } \\
\hline I-II & 1 & 14.3 & 62 & 33.5 & 0 & 0 & 19 & 32.2 & 1 & 25.0 & 43 & 34.1 \\
\hline III-IV & 6 & 85.7 & 123 & 66.5 & 3 & 100 & 40 & 67.8 & 3 & 75.0 & 83 & 65.9 \\
\hline \multicolumn{13}{|l|}{ HBsAb } \\
\hline \multicolumn{13}{|l|}{ Rituximab } \\
\hline- & 0 & 0 & 39 & 21.1 & 0 & 0 & 12 & 20.3 & 0 & 0 & 27 & 21.4 \\
\hline+ & 7 & 100 & 146 & 78.9 & 3 & 100 & 47 & 79.7 & 4 & 100 & 99 & 78.6 \\
\hline
\end{tabular}

2 Abbreviations: HBV, hepatitis B virus; NHL, non-Hodgkin lymphoma; HBsAg, hepatitis B surface antigen; HBcAb, hepatitis B core antibody; HBsAb, hepatitis

3 B surface antibody 
Table 3(on next page)

Details of HBV reactivation and HBV-related hepatitis flares in the HBsAg-positive patients 
1 Table 3. Details of $\mathrm{HBV}$ reactivation and $\mathrm{HBV}$-related hepatitis flares in the $\mathrm{HBs} A g$-positive patients

\begin{tabular}{|c|c|c|c|c|c|c|c|c|c|c|c|c|c|}
\hline $\begin{array}{l}\text { Patient } \\
\text { number }\end{array}$ & Sex & Age & diagnosis & Stage & $\mathrm{HBsAb}$ & $\begin{array}{l}\text { Baseline } \\
\text { HBVDNA } \\
\text { level } \\
(\mathrm{KIU} / \mathrm{ml})\end{array}$ & $\begin{array}{l}\text { Prophylaxis } \\
\text { Anti-HBV } \\
\text { agents }\end{array}$ & $\begin{array}{l}\text { Treatment } \\
\text { regimen } \\
\text { (\# of } \\
\text { courses) }\end{array}$ & $\begin{array}{l}\text { Time to HBV } \\
\text { reactivation } \\
\text { (months) }\end{array}$ & $\begin{array}{l}\text { HBV DNA } \\
\text { level when } \\
\text { reactivation } \\
(\mathrm{KIU} / \mathrm{ml})\end{array}$ & $\begin{array}{l}\text { Hepatitis } \\
\text { flare } \\
\text { (ALT level } \\
\text { IU/L) }\end{array}$ & $\begin{array}{l}\text { Outcome and } \\
\text { anti-viral } \\
\text { treatment after } \\
\text { HBV } \\
\text { reactivation }\end{array}$ & $\begin{array}{l}\text { Survival } \\
\text { state }\end{array}$ \\
\hline 1 & Male & 62 & FL & 4 & Unknown & 0.727 & Telbivudine & $\begin{array}{l}\text { R-CHOP } \\
\text { (8) }\end{array}$ & $\begin{array}{l}11.2 \text { months after } \\
\text { withdrawal of } \\
\text { prophylaxis } \\
\text { (late } \\
\text { reactivation) }\end{array}$ & 44700 & Yes (137) & $\begin{array}{l}\text { ALT normal, } \\
\text { HBV DNA } \\
\text { level } \\
\text { undetectable } \\
\text { after } 7.9 \\
\text { months of } \\
\text { entecavir }\end{array}$ & Alive \\
\hline 2 & Female & 37 & FL & 4 & Negative & 5.04 & Entecavir & $\begin{array}{l}\text { R-CHOP } \\
\text { (8) with R } \\
\text { maintain } \\
\text { (8) }\end{array}$ & $\begin{array}{l}\text { During } \\
\text { chemotherapy, } \\
12.7 \text { months after } \\
\text { the first time of } \\
\text { chemotherapy }\end{array}$ & 92200 & $\begin{array}{l}\text { No } \\
(28)\end{array}$ & $\begin{array}{l}\text { Last HBV } \\
\text { DNA level } \\
0.618 \\
(\mathrm{KIU} / \mathrm{ml}) \text { after } \\
18.6 \text { months } \\
\text { of tenofovir }\end{array}$ & Alive \\
\hline 3 & Male & 67 & $\begin{array}{l}\text { DLBCL } \\
(\mathrm{HCC})\end{array}$ & 4 & Positive & 27.8 & $\begin{array}{l}\text { Tenofovir } \\
\text { for } 2 \text { years } \\
\text { then } \\
\text { switched to } \\
\text { Lamivudine }\end{array}$ & $\begin{array}{l}\text { RCHOP } \\
(5) \\
\text { RESHAP } \\
\text { (4) }\end{array}$ & $\begin{array}{l}15.4 \text { months after } \\
\text { the last time of } \\
\text { chemotherapy } \\
\text { but still on } \\
\text { lamivudine }\end{array}$ & 85900 & $\begin{array}{l}\text { Yes } \\
(2050)\end{array}$ & $\begin{array}{l}\text { Tenofovir and } \\
\text { entecavir for } \\
\text { one week and } \\
\text { die due to } \\
\text { hepatic failure }\end{array}$ & $\begin{array}{l}\text { Died of } \\
\text { hepatic } \\
\text { failure }\end{array}$ \\
\hline
\end{tabular}




\begin{tabular}{|l|l|l|l|l|l|l|l|l|l|l|l|}
\hline & & & & & & & & & & & \\
\end{tabular}

2 Abbreviations: ALT,alanine transaminase; DLBCL, diffuse large B cell lymphoma; FL, follicular lymphoma; HCC, hepatocellular carcinoma; R-CHOP,

3 rituximab, cyclophosphamide, doxorubicin, vincristine, and prednisolone; R-ESHAP, rituximab, etoposide, solu-medrol, cytarabine, and cisplatin; HBsAg,

4 hepatitis B surface antigen; HBsAb, hepatitis B surface; R maintain, Rituximab maintenance. 


\section{Table 4 (on next page)}

Details of HBV reactivation and HBV-related hepatitis flares in the patients with resolved HBV infections 
1 Table 4. Details of $\mathrm{HBV}$ reactivation and $\mathrm{HBV}$-related hepatitis flares in the patients with resolved $\mathrm{HBV}$ infections

\begin{tabular}{|c|c|c|c|c|c|c|c|c|c|c|c|}
\hline $\begin{array}{l}\text { Patient } \\
\text { number }\end{array}$ & Sex & $\begin{array}{l}\text { Age } \\
\text { (years) }\end{array}$ & diagnosis & Stage & Anti-HBs & $\begin{array}{l}\text { Treatment } \\
\text { regimen } \\
\text { (\# of cycles) }\end{array}$ & $\begin{array}{l}\text { HBV reactivation } \\
\text { time }\end{array}$ & $\begin{array}{l}\text { HBV } \\
\text { DNA } \\
(\mathrm{KIU} / \mathrm{ml})\end{array}$ & $\begin{array}{l}\text { Hepatitis } \\
\text { flare } \\
\text { (ALT level: } \\
\text { IU/L) }\end{array}$ & $\begin{array}{l}\text { Outcome and } \\
\text { anti-viral } \\
\text { treatment after } \\
\text { HBV } \\
\text { reactivation }\end{array}$ & $\begin{array}{l}\text { Survival } \\
\text { state }\end{array}$ \\
\hline 1 & Female & 68 & FL & 4 & Negative & RCHOP (8) & $\begin{array}{l}36.3 \text { months after last } \\
\text { course of R-CHOP } \\
\text { (late reactivation) }\end{array}$ & $2.52^{*}$ & Yes (537) & $\begin{array}{l}\text { ALT normal, } \\
\text { HBV DNA } \\
\text { level } \\
\text { undetectable } \\
\text { after } 13.9 \\
\text { months of } \\
\text { lamivudine }\end{array}$ & Alive \\
\hline 2 & Male & 50 & $\begin{array}{l}\text { Marginal } \\
\text { zone B cell } \\
\text { lymphoma } \\
\text { and } \\
\text { transform } \\
\text { to DLBCL }\end{array}$ & 4 & Positive & $\begin{array}{l}\text { CHOP (8), } \\
\text { ESHAP (6), } \\
\text { R-ICE (5), } \\
\text { auto-HSCT } \\
\text { EPOCH (1) }\end{array}$ & $\begin{array}{l}\text { During treatment, } \\
56.0 \text { months after } 1 \mathrm{st} \\
\text { course of } \\
\text { chemotherapy }\end{array}$ & 124000 & Yes (121) & $\begin{array}{l}\text { ALT normal, } \\
\text { last HBV DNA } \\
\text { level: } 0.445 \\
\text { KIU/ml after } \\
4.3 \text { months of } \\
\text { tenofovir }\end{array}$ & $\begin{array}{l}\text { Died of } \\
\text { lymphoma } \\
\text { progression }\end{array}$ \\
\hline 3 & Male & 73 & DLBCL & 2 & Positive & RCHOP (6) & $\begin{array}{l}8.4 \text { months after last } \\
\text { course of R-CHOP }\end{array}$ & 12200 & Yes (863) & $\begin{array}{l}\text { ALT normal, } \\
\text { HBV DNA } \\
\text { level } \\
\text { undetectable } \\
\text { after entecavir }\end{array}$ & Alive \\
\hline
\end{tabular}




\begin{tabular}{|c|c|c|c|c|c|c|c|c|c|c|c|}
\hline & & & & & & & & & & $\begin{array}{l}\text { and lamivudine } \\
\text { together for } 2 \\
\text { weeks and then } \\
\text { only entecavir } \\
\text { for } 3.9 \text { months }\end{array}$ & \\
\hline 4 & Male & 60 & FL & 4 & Positive & $\begin{array}{l}\text { RCHOP (5) } \\
\text { followed by R } \\
\text { maintain }(8)\end{array}$ & $\begin{array}{l}\text { During treatment, } \\
24.5 \text { months after } 1 \mathrm{st} \\
\text { course of } \\
\text { chemotherapy, }\end{array}$ & $>170000$ & No (98) & $\begin{array}{l}\text { Just start } \\
\text { tenofovir } \\
\text { treatment and } \\
\text { still pending the } \\
\text { HBV DNA } \\
\text { level data }\end{array}$ & Alive \\
\hline
\end{tabular}

2 Abbreviations: ALT, alanine transaminase; DLBCL, diffuse large B cell lymphoma; EPOCH, etoposide, prednisolone, vincristine, cyclophosphamide, and doxorubicin;ESHAP,

3 etoposide, solu-medrol, cytarabine, and cisplatin; FL, follicular lymphoma; HSCT, hematopoietic stem cell transplantation; (R)-CHOP, (rituximab)-cyclophosphamide,

4 doxorubicin, vincristine, and prednisolone; ESHAP, etoposide, solu-medrol, cytarabine, and cisplatin; R-ICE, rituximab- ifosfamide, carboplatin, etoposide; HBsAg, hepatitis B

5 surface antigen; HBcAb, hepatitis B core antibody; HBsAb, hepatitis B surface antibody; R maintain, Rituximab maintenance.*: HBV viral load data was checked after anti-viral

6 treatment 


\section{Table 5 (on next page)}

Cox proportional hazard ratios for mortality in NHL patients 
1

Table 5. Cox proportional hazard ratios for mortality in NHL patients

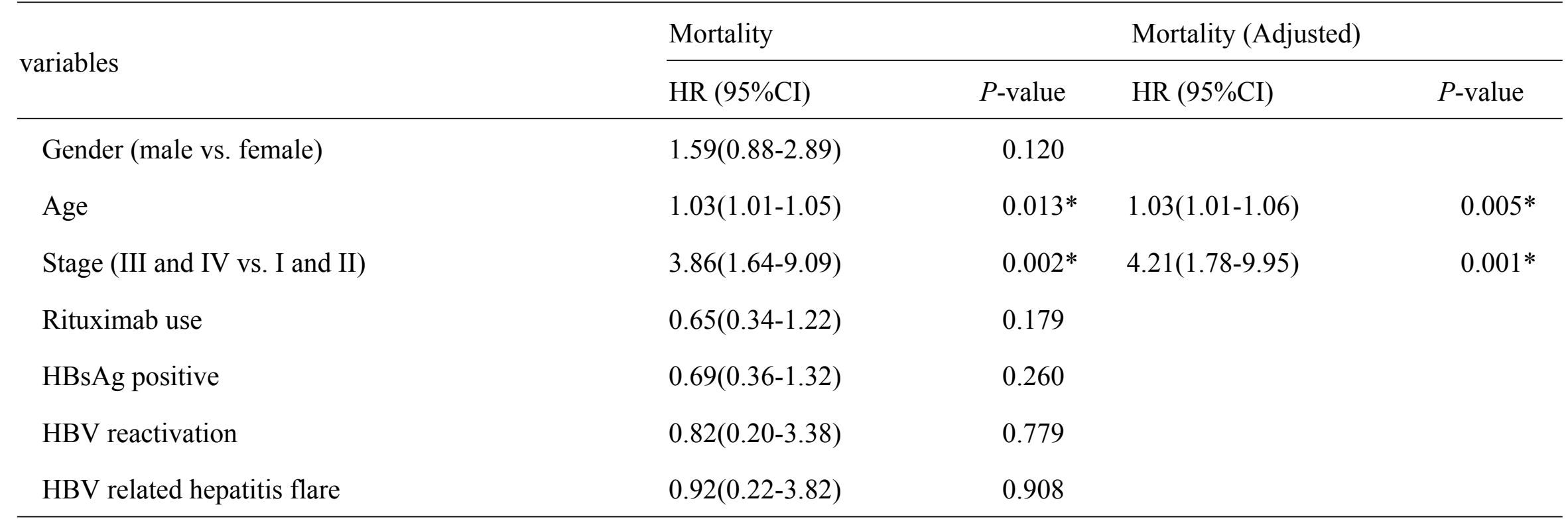

2 Abbreviations: CI: confidence interval, HR: hazard ratio, NHL: non-Hodgkin lymphoma

$3 *: \mathrm{p}<0.05$ 